2. Bobby JJ, Emami JM, Farmer RDT, Newman CGH. Operative survival and 40 year follow up of surgical repair of aortic coarctation. Br Heart J 1991;65:271-6.

3. Cohen M, Fuster V, Steele PM, Driscoll D, McGoon DC. Coarctation of the aorta: long-term follow-up and prediction of outcome after surgical correction. Circulation 1989;80: 840-5.
4. Del Nido PJ, Williams WG, Wilson GJ, Coles JG, Moes CAF, Hosokawa Y, et al. Synthetic patch angioplasty repair of coarctation of the aorta: experience with aneurysm formation. Circulation 1986;74(Suppl):I32-6.

5. Williams CR, Nilakhe V, Clouse ME. Acute aortic occlusion as a late complication of coarctation repair. Cardiovasc Intervent Radiol 1989;12:286-9.

\title{
ENDOBRONCHIAL TUMOR EMBOLISM: A PREVENTABLE CAUSE OF DEATH
}

\author{
V. Pathi, FRCS, MRCP, P. Ramphal, MBBS, F. Sutherland, FRCS, and A. Kirk, MD, FRCS, Glasgow, Scotland
}

During the past decade, improvements in anesthesia and surgical techniques have made pulmonary resection amongst the safest of major operative procedures. The routine use of the double-lumen endotracheal tube has allowed the operation to be carried out in a more comfortable manner, maintaining oxygen saturation without

From the Department of Cardiothoracic Surgery, Western Infirmary, Dumbarton Rd., Glasgow, Scotland, United Kingdom.

Received for publication Jan. 24, 1996; accepted for publication Feb. 5, 1996.

J Thorac Cardiovasc Surg 1996;112:844-5

Copyright $(1096$ by Mosby-Year Book, Inc.

$0022-5223 / 96 \$ 5.00+0 \quad \mathbf{1 2 / 5 4 / 7 2 5 6 0}$ obscuring the operative field. We report a case in which the inability to pass such a tube led to disastrous consequences.

Case report. A 76-year-old woman had a history of breathlessness, cyanosis, and left-sided chest pain. Clinical examination and chest radiography confirmed complete collapse of the left lung (Fig. 1). Bronchoscopy was performed and revealed tumor originating from the left upper lobe and involving the left main bronchus. A carcinosarcoma was proved by histologic examination. Because mediastinoscopic results were negative for nodal involvement, the patient was prepared for operation.

In the anesthesia room, a long $8 \mathrm{~F}$ single-lumen endotracheal tube was inserted for ventilation because of the small size of the patient's trachea. A routine left thora-

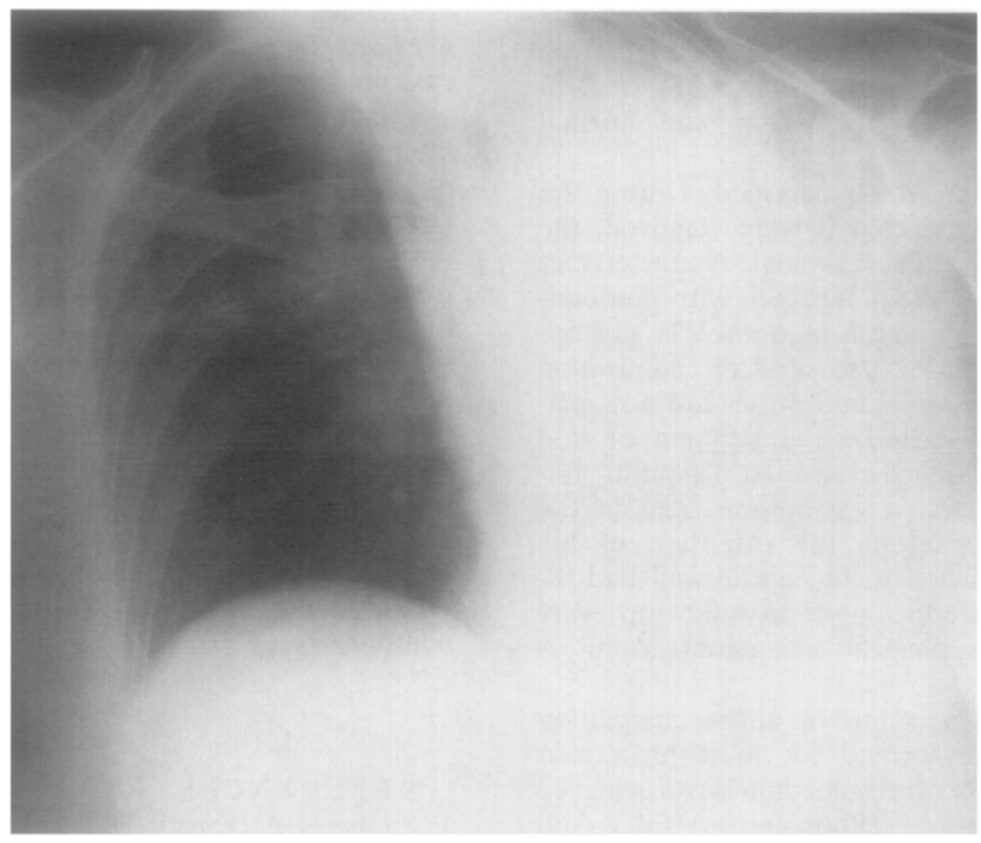

Fig. 1. Chest radiograph of patient displays complete collapse of left lung. 


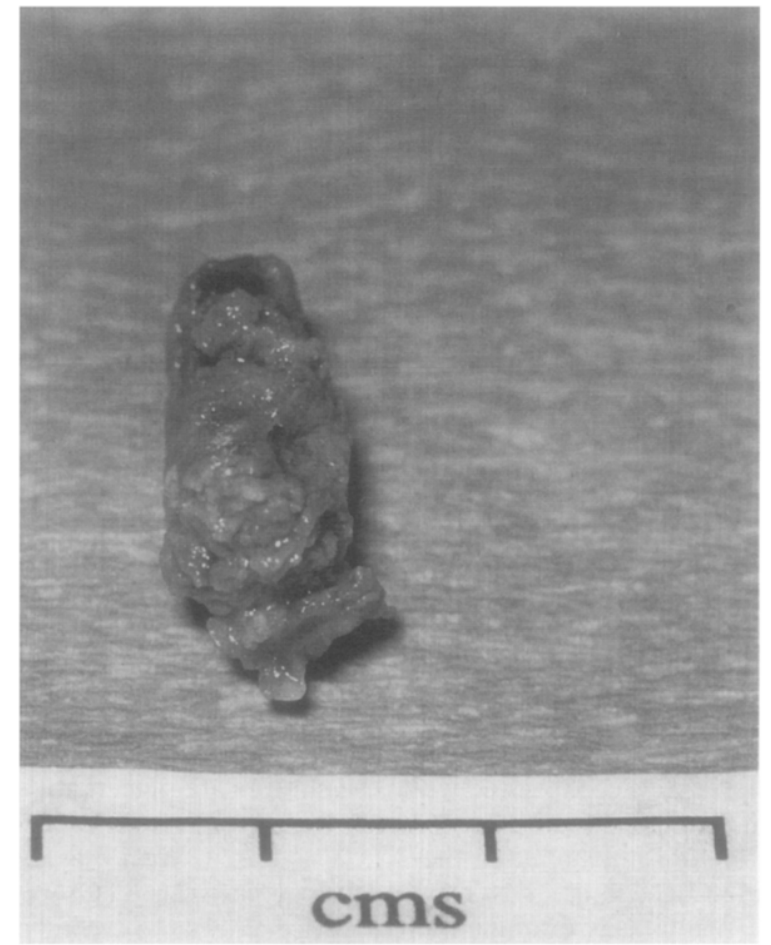

Fig. 2. Embolic core of tumor retrieved from right main bronchus with a rigid bronchoscope.

cotomy was performed through the bed of the sixth rib and the pleural cavity was entered. The lung was mobilized by division of the pleural adhesions, and attention was then turned to the hilum. Before any dissection of the hilum could be carried out, there was a sudden rise in airway inflation pressure. As a consequence, the patient could not be ventilated. Because of the rapid drop in oxygen saturation, the patient was turned to the supine position, the endotracheal tube was removed, and a rigid bronchoscope was inserted. Complete obstruction of the right main bronchus by a core of tumor was revealed (Fig. 2). Once this tumor core was removed with biopsy forceps, ventilation was again commenced without incident. Another long single-lumen tube was passed, with confirmation of position in the right main bronchus by bronchoscopy. The pneumonectomy was then completed, but during closure of the chest the patient had a cardiac arrest from which she could not be resuscitated. Autopsy revealed the presence of triple-vessel coronary artery dis- ease with an old inferior infarction. No remaining tumor emboli were seen in the right bronchus.

Comment. The combination of the routine use of the double-lumen tube and selective underreporting of surgical mishaps has resulted in a paucity of publications on the subject of endobronchial tumor embolism in the Englishlanguage literature. ${ }^{1}$ Existing reports do, however, stress that airway obstruction from this cause can occur at any time during or after surgical manipulation of the bronchus. $^{2,3}$ Emboli have also been seen to lodge as high as the larynx or to travel peripherally to occlude the bronchi. In one of these cases, the use of a double-lumen tube only delayed the occurrence of the embolus until the postoperative period. Such cases are extremely rare, however, and some degree of protection from such a catastrophe can be expected from the use of an endobronchial tube, particularly when bronchoscopy has revealed the presence of a friable, centrally placed tumor. ${ }^{4}$ Most reported cases have been either squamous cell or carcinosarcomas, both of which are known to be friable tumors. An alternative approach, when it is believed that use of a large doublelumen tube may lead to tracheal rupture, would be to use a long single-lumen tube with its cuff inflated endobronchially. Constant confirmation of the position of the tube by flexible bronchoscopy should prevent obstruction of the right upper bronchus orifice or retraction of the tube into the trachea, as occurred in our patient.

Early diagnosis and reversal of this catastrophe can only be achieved by immediate bronchoscopy and extraction of the tumor. This can be achieved externally by means of a rigid instrument or through the bronchial stump with a flexible endoscope. ${ }^{1,2}$ This is much more difficult in the postoperative period and requires the availability of immediate bronchoscopic facilities in the recovery ward. The frailty of this group of patients, however, makes their survival from this major insult unlikely. Often, they have coexisting cardiovascular conditions that may not allow them to tolerate even a brief episode of hypoxia.

\section{REFERENCES}

1. Bollen EC, Van Duin CJ, Van Noord JA, Janssen JG, Theunissen PH. Tumour embolus in lung surgery. Eur J Cardiothorac Surg 1993;7:104-6.

2. Barat G, Ascorv A, Avello F. Unusual airway obstruction during pneumonectomy. Anaesthesia 1976;31:1290-1.

3. DeLange JJ, Van Mourick JC, Den Otter G. Fatal complication after pneumonectomy. Ned Tijdschr Genuskd 1989;133: 32-4.

4. Heydorn WH, Barry MJ, Zajtchuk R, Strevey TE. Tumour embolus as a cause of death during pneumonectomy. $J$ Thorac Cardiovasc Surg 1974;67:308-9. 